\title{
Adsorption of polyethylene glycol (PEG) from aqueous solution onto hydrophobic zeolite
}

\author{
C.Y. Chang, ${ }^{a}$ W.T. Tsai, ${ }^{b, *}$ C.H. Ing, ${ }^{a}$ and C.F. Chang ${ }^{a}$ \\ ${ }^{a}$ Graduate Institute of Environmental Engineering, National Taiwan University, Taipei 106, Taiwan, ROC \\ ${ }^{\mathrm{b}}$ Department of Environmental Engineering and Health, Chia Nan University of Pharmacy and Science, Tainan 717, Taiwan, ROC
}

Received 14 September 2002; accepted 25 November 2002

\begin{abstract}
In the present study, a hydrophobic zeolite was used as an adsorbent for the adsorption of polyethylene glycol (PEG) in water solution and electroplating solution at $25^{\circ} \mathrm{C}$. The adsorption capacities were determined through the adsorption isotherms in a thermostated shaker. The rate of adsorption, on the other hand, was investigated in a batch adsorber under controlled process parameters such as initial PEG concentration $\left(30,70,110,150,200\right.$, and $\left.300 \mathrm{mg} \mathrm{dm}^{-3}\right)$, agitation speed $(200,800$, and $1000 \mathrm{rpm})$, and adsorbent particle size $(0.72$, 1.44 , and $2.03 \mathrm{~mm}$ ). A batch kinetic model, according to a pseudo-second-order mechanism, has been tested to predict the rate constant of adsorption, equilibrium adsorption capacity, time of half-adsorption, and equilibrium concentration by the fitting of the experimental data. The results of the adsorption isotherm and kinetic studies show that the adsorption process can well be described with the Langmuir and Freundlich models and the pseudo-second-order equation, respectively. Comparing the values of adsorption parameters of PEG in water solution and electroplating solution, there are no significant differences. In addition, the effective diffusion coefficient of the PEG molecule in the microporous adsorbent has been estimated at about $3.20 \times 10^{-8} \mathrm{~cm}^{2} \mathrm{~s}^{-1}$ based on the restrictive diffusion model.
\end{abstract}

(C) 2003 Elsevier Science (USA). All rights reserved.

Keywords: Liquid-phase adsorption; Polyethylene glycol; Hydrophobic zeolite; Isotherm; Kinetic modeling; Restrictive diffusion

\section{Introduction}

Recently, copper electroplating has been applied to the formation of microelectronics for printed wiring boards (PWB) and ultra-large-scale integration (ULSI) [1], parallel to the rapid growth of the PWB and semiconductor manufacturing industries in Taiwan since the mid-1990s. However, the wasted electroplating solution may become one of the major wastewater sources in the PWB industry because the main components of the electroplating solution include copper sulfate, sulfuric acid, hydrochloric acid, and some minor additives such as polyethylene glycol (PEG), which is a neutral surfactant and acts as a brightener and stabilizer enhancing the copper deposition rate [2]. Therefore, the effluent discharged from the metal finishing industry must also comply with the stringent standards of chemical oxygen demand (COD) for water quality control, i.e., $120 \mathrm{mg} \mathrm{dm}^{-3}$ for the PWB manufacturing industry according to the Efflu-

\footnotetext{
* Corresponding author.

E-mail address: wwtsai@mail.chna.edu.tw (W.T. Tsai).
}

ent Standards in Taiwan [3]. Obviously, an advanced process needs to be adopted for industrial wastewater treatment.

There are two principal treatment processes for physicochemical removal of PEG in water and wastewater: destructive processes such as ozonation [4-7], ozonation/UV [8], or $\mathrm{H}_{2} \mathrm{O}_{2} / \mathrm{UV}$ oxidation [9], and recuperative processes such as adsorption into activated carbon [10-12] or montmorillonite clay [13]. However, in wastewater treatment it is well known that the adsorption process has been considered as the best available technology for removing organic pollutants [14,15]. Suzuki et al. [10] studied the adsorption of PEG with molecular weight less than 1500 onto activated carbon to elucidate the limiting adsorption due to limited access to the interior pore structure of carbon adsorbents. Arbuckle and Osman [11] used a series of PEG molecules adsorbed onto activated carbon to expand the Suzuki study. They found the maximum adsorption loading occurred with the soluble polymer in the molecular weight range 1000 to 8000 , implying restrictive or hindered adsorption as the molecular weight or size of PEG is compared to the pore size of activated carbon. Chang et al. [12] examined the ad- 
sorption equilibrium of PEG with large molecular weight (ave. 6000) from copper electroplating solutions on activated carbon at $288-313 \mathrm{~K}$, and investigated the feasibility of removing the organic additive from the bath. Zhao et al. [13] reported on adsorption of PEG with molecular weight 300-200,000 onto montmorillonite clays; they found the adsorption rate was rapid, and equilibrium was attained within $30 \mathrm{~min}$. Also, the adsorption capacities for all of the clay adsorbents approached constants for molecular weight of PEG over approximately 2000.

Although activated carbons are the most widely used adsorbent in the removal or recovery of organic compounds from liquid-phase streams due to their large surface area and nearly nonpolar surface [16], they still present some disadvantages in that they are flammable materials, difficult to regenerate high-boiling organics, and may promote polymerization of some polymerizable compounds [17]. On the other hand, hydrophobic zeolite or zeolite DAY, a new synthetically produced adsorbent with high $\mathrm{Si} / \mathrm{Al}$ ratio, does not have these disadvantages and exhibits good adsorption capacity, similar to that of activated carbon. In contrast to the progress in research on PEG adsorption onto activated carbon, fundamental studies on the adsorption of PEG onto hydrophobic zeolite are scarce. Further, it is noted that the polarity of PEG weakens and the affinity of PEG to water molecules decreases with the increase of its molecular weight [13]. Thus, the main object of this paper is to study the adsorption equilibrium and adsorption rate or kinetics of PEG with large molecular weight in water solution and copper electroplating solution at $25^{\circ} \mathrm{C}$, to further evaluate the applicability of common isotherm models (i.e., Langmuir and Freundlich) and the pseudo-second-order rate model of using this inorganic adsorbent for the removal of PEG from aqueous system. In addition, this paper also determines the effective diffusion coefficient, which was estimated based on the restrictive diffusion model, in order to relate to the slow adsorption process when the molecular size of a solute is comparable to the pore size of an adsorbent.

\section{Materials and methods}

\subsection{Materials}

The adsorbate used in the adsorption experiments is polyethylene glycol (PEG), which was purchased from Merck Co. (Catalog No. 807491). The general formula of PEG is $\mathrm{H}\left(\mathrm{OCH}_{2} \mathrm{CH}_{2}\right)_{n} \mathrm{OH}$, where its molecular weight (MW) is in the range of 5000-7000 with average value of $n$ between 109 and 158. Hydrophobic zeolite DAY, supplied by Degussa AG (Germany) and commercially prepared via dealumination of sodium Y-zeolite, was employed as adsorbent in the present study. The zeolite was crushed and sieved to mesh ranges of 20 to 30 (average particle size, $0.72 \mathrm{~mm}$ ), washed with deionized water to remove the suspension residues, dried at $105^{\circ} \mathrm{C}$ for at least $24 \mathrm{~h}$, and finally stored in the desiccator. Its physical properties were as follows [18]: BET surface area, $601 \mathrm{~m}^{2} \mathrm{~g}^{-1}$; total pore volume, $0.237 \mathrm{~cm}^{3} \mathrm{~g}^{-1}$; true density, $2.38 \mathrm{~g} \mathrm{~cm}^{-3}$; particle density estimated from total pore volume and true density [19], $1.52 \mathrm{~g} \mathrm{~cm}^{-3}$; particle porosity computed from particle density and true density [19], 0.36. Obviously, the material is a microporous adsorbent having an average pore diameter around $15.8 \AA$, calculated from BET surface area and total pore volume, if the pores are straight, cylindrical, and not interconnected [19]. In addition, its main components are $\mathrm{SiO}_{2}$ and $\mathrm{Al}_{2} \mathrm{O}_{3}$, having a high Si/Al ratio (>100), which makes the zeolite hydrophobic [20].

\subsection{Methods}

\subsubsection{Adsorption equilibrium}

The adsorption equilibrium of PEG was determined by using the batch-shaking method as previously described [12]. In each isotherm experiment, adsorption was carried out by shaking with a fixed value (i.e., $\left.0.1 \mathrm{dm}^{3}\right)$ of PEG $(0.1 \mathrm{~g})$ solutions at different initial concentrations $(35,70,100,150$, 200, and $300 \mathrm{mg} \mathrm{dm}^{-3}$ ) in a thermostated shaker bath at $25 \pm 0.1{ }^{\circ} \mathrm{C}$ for all experiments. These PEG solutions were contacted for about $380 \mathrm{~h}$, which had been shown in the preliminary adsorption kinetics experiments and the system of PEG adsorption onto microporous carbon adsorbent [12], and was well in excess of the contact time requirement established to reach equilibrium. Equilibrium concentration analysis of the solutions after filtration with a $0.45-\mu \mathrm{m}$ fiber membrane was carried out by a TOC analyzer (O.I.C., Model 700) [7,8,12]. The amount of PEG adsorbed was determined by the difference of the initial and equilibrium liquid-phase concentrations. The amount of PEG adsorbed, $q_{e}$, was determined as

$q_{e}=\left(C_{0}-C_{e}\right) V / W$,

where $C_{0}$ and $C_{e}$ are the initial and equilibrium liquidphase concentrations of PEG solution, respectively, $V$ is the volume of the PEG solution, and $W$ is the mass of the dry zeolite sample.

\subsubsection{Adsorption kinetics}

For all of the adsorption kinetics experiments, about $3 \mathrm{~g}$ of the zeolite was put into a $5-\mathrm{dm}^{3}$ stirred batch adsorber with four baffles in the wall. The adsorber was maintained at $25^{\circ} \mathrm{C}$ by water jacket from a refrigerated circulatingwater bath prior to the experiment. In each experiment, ca. $3.7 \mathrm{dm}^{3}$ of the PEG solution was continuously stirred and samples of the solution (ca. $20 \mathrm{~cm}^{3}$ ) were withdrawn from the adsorber at different intervals until no significant change in the PEG concentration was measured. It was then filtrated with centrifuge filtration. The concentration analysis of filtrate PEG solution was immediately measured with a TOC analyzer (O.I.C., Model 700). The amount of PEG adsorbed was determined as

$q_{t}=\left(C_{0}-C_{t}\right) V / W$, 
where $C_{0}$ and $C_{t}$ are the initial and liquid-phase concentrations of the PEG solution at time $t$, respectively, $V$ is the volume of the PEG solution, and $W$ is the mass of the dry adsorbent. The effects of experimental parameters, such as the initial PEG concentration $(30,70,110,150,200$, and $\left.300 \mathrm{mg} \mathrm{dm}^{-3}\right)$, stirring rate $(200,800$, and $1000 \mathrm{rpm})$, and adsorbent size $(2.03,1.44$, and $0.72 \mathrm{~mm})$, were investigated in the present study. In each experiment, the adsorption was carried out under conditions where one parameter changed at a time while the other parameters were held constant.

\subsubsection{Adsorption of electroplating solution}

To simulate the adsorption of electroplating solution, bath solutions of $0.1 \mathrm{dm}^{3}$ were prepared with $\mathrm{H}_{2} \mathrm{SO}_{4}$ of $17 \mathrm{~g} \mathrm{dm}^{-3}, \mathrm{HCl}$ of $7.6 \mathrm{~g} \mathrm{dm}^{-3}, \mathrm{CuSO}_{4} \cdot 5 \mathrm{H}_{2} \mathrm{O}$ of $200 \mathrm{~g} \mathrm{dm}^{-3}$, and $30-300 \mathrm{mg} \mathrm{dm}^{-3}$ of PEG in the isotherm experiments described previously. Further, adsorption kinetics of electroplating solution with initial concentration $70 \mathrm{mg} \mathrm{dm}^{-3}$ in a stirred batch adsorber was tentatively examined to evaluate the differences between the PEG adsorption of electroplating solutions and that of water solutions, also described previously.

\section{Results and discussion}

\subsection{Adsorption isotherm in water solution}

In order to optimize the design of an adsorption system to remove the organic pollutant, it is important to establish the most appropriate correlations for the equilibrium data for each system. Two common isotherm equations have been tested in the present study: Langmuir and Freundlich models $[14,15]$. Applicability of the isotherm equations was compared by judging the correlation coefficients, $R^{2}$.

\subsubsection{Langmuir model}

The Langmuir equation is the most widely used twoparameter equation, commonly expressed as

$C_{e} / q_{e}=1 /\left(K_{L} q_{m}\right)+\left(1 / q_{m}\right) C_{e}$.

In Eq. (3), $C_{e}$ and $q_{e}$ are as defined in Eq. (1), $K_{L}$ is a direct measure for the intensity of the adsorption process, and $q_{m}$ is a constant related to the area occupied by a monolayer of absorbate, reflecting the adsorption capacity. From a plot of $C_{e} / q_{e}$ vs $C_{e}, q_{m}$, and $K_{L}$ can be determined from the slope and intercept. Table 1 presents the results of the Langmuir

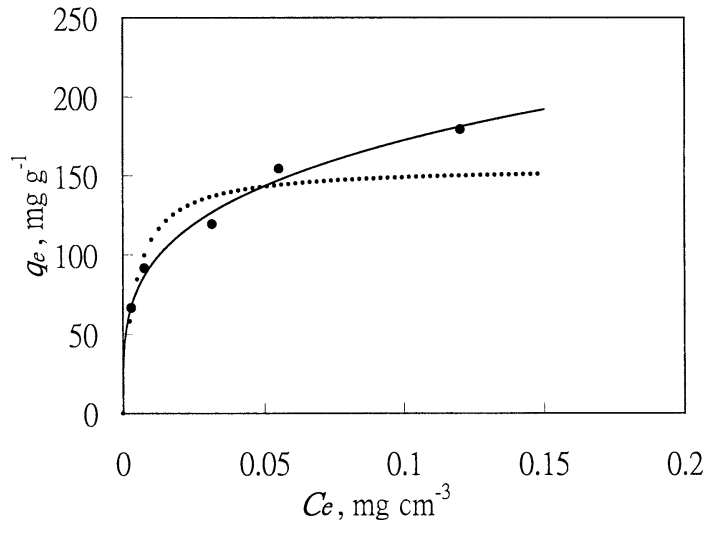

Fig. 1. Isothermal adsorption of PEG in water solution onto zeolite DAY at $25^{\circ} \mathrm{C}$. - experimental data; - , simulation of Freundlich model; $\cdots$, simulation of Langmuir model.

isotherm fits of PEG to the measured adsorption capacity data at $25^{\circ} \mathrm{C}$. The Langmuir isotherm appears to fit the data reasonably well, as reflected by correlation coefficients $\left(R^{2}\right)$ in the range of 0.94 . Figure 1 shows such a Langmuir isotherm fit for the adsorption of PEG onto zeolite DAY.

\subsubsection{Freundlich model}

The Freundlich isotherm is an empirical equation and has been shown to be satisfactory for low concentrations. The equation is commonly given by

$q_{e}=K_{F} C_{e}^{1 / n}$,

where $K_{F}$ is a constant for the system, related to the bonding energy. $K_{F}$ can be defined as an adsorption or distribution coefficient and represents the quantity of adsorbate adsorbed onto adsorbents for a unit equilibrium concentration (i.e., $C_{e}=1 \mathrm{mg} \mathrm{dm}^{-3}$ ). The slope $1 / n$, ranging between 0 and 1 , is a measure for the adsorption intensity or surface heterogeneity, becoming more heterogeneous as its value gets closer to zero. A value for $1 / n$ below one indicates a normal Langmuir isotherm while $1 / n$ above one is indicative of cooperative adsorption. A plot of $\ln q_{e}$ vs $C_{e}$ enables the empirical constants $K_{F}$ and $1 / n$ to be determined from the intercept and slope of the linear regression. Table 1 presents the Freundlich parameters, also indicating the satisfactorily good correlation between the model predictions and the experimental data. The value of the exponent $n$ is 3.76 , depicting favorable adsorption in the present study. On the other hand, it can be seen that the Freundlich model yields a somewhat better fit than the Langmuir model by comparing the results of correlation coefficients (i.e., 0.99 vs 0.94 ) in

Table 1

Isotherm parameters for adsorption of PEG onto zeolite DAY in water and copper electroplating solutions

\begin{tabular}{|c|c|c|c|c|c|c|}
\hline \multirow[t]{2}{*}{ Solution } & \multicolumn{3}{|c|}{ Langmuir } & \multicolumn{3}{|c|}{ Freundlich } \\
\hline & $\begin{array}{c}q_{m} \\
\left(\mathrm{mg} \mathrm{g}^{-1}\right)\end{array}$ & $\begin{array}{c}K_{L} \\
\left(\mathrm{~cm}^{3} \mathrm{mg}^{-1}\right)\end{array}$ & $R^{2}$ & $\begin{array}{c}K_{F} \\
{\left[\mathrm{mg} \mathrm{g}^{-1}\left(\mathrm{~cm}^{3} \mathrm{mg}^{-1}\right)^{1 / n}\right]}\end{array}$ & $1 / n$ & $R^{2}$ \\
\hline Water & 155.1 & 234.4 & 0.9393 & 317.9 & 3.76 & 0.9856 \\
\hline Copper electroplating & 144.3 & 200.3 & 0.9660 & 482.8 & 2.51 & 0.9944 \\
\hline
\end{tabular}


Table 1. It is also seen (Fig. 1) that the data for each adsorption isotherm closely lie on the Freundlich line as expected by Eq. (4).

\subsection{Adsorption kinetics}

The adsorption process on a porous adsorbent in a stirring chamber generally involves several transport stages [14,15]; external diffusion, internal diffusion, and actual adsorption. The model for the separation process should adequately account for the mass balance and the equilibrium isotherm if the system is isothermal. In most cases, the resistance to internal diffusion can be significant. However, the local rate of adsorption is assumed to be relatively fast and the resistance to external diffusion is experimentally controlled to be negligible, compared to the intraparticle diffusion. Although many theoretical model equations have been proposed to describe the adsorption kinetics based on mass balance, pore diffusion rate, and initial/boundary conditions, these equations are not only complicated and impractical in industry, but also require detailed data such as the characteristics of adsorbate and adsorbent.

In the present work, a simple kinetic analysis of adsorption, a pseudo-second-order equation, was used to fit experimental data in the form [21-23]

$\mathrm{d} q_{t} / d t=k\left(q_{e}-q_{t}\right)^{2}$,

where $k$ is the pseudo-second-order rate constant $\left(\mathrm{g} \mathrm{mg}^{-1}\right.$ $\left.\mathrm{h}^{-1}\right), q_{e}$ is the amount of PEG adsorbed at equilibrium $\left(\mathrm{mg} \mathrm{g}^{-1}\right)$, and $q_{t}$ is the amount of PEG adsorbed at time $t\left(\mathrm{mg} \mathrm{g}^{-1}\right)$. Integrating Eq. (5) for the boundary conditions $t=0$ to $t=t$ and $q_{t}=0$ to $q_{t}=q_{t}$ gives

$1 /\left(q_{e}-q_{t}\right)=1 / q_{e}+k t$.

Equation (6) can be rearranged to obtain a linear form,

$t / q_{t}=1 /\left(k q_{e}^{2}\right)+\left(1 / q_{e}\right) t$.

Rate parameters, $k$ and $q_{e}$, can be directly obtained from the intercept and slope of the plot of $\left(t / q_{t}\right)$ against $t$. The equilibrium concentration (i.e., $C_{e}$ ) can be further calculated from Eq. (1) as the value of $q_{e}$ has been obtained from the fitting of Eq. (7). Also, half of the PEG adsorption time, $t_{1 / 2}$, is the time required for the adsorbent to take up half as much PEG as it will at equilibrium (i.e., $t=t_{1 / 2}$ as $q_{t}=q_{e} / 2$ ). This time is often used as a measure of the rate of adsorption and is given from the rearrangement of Eq. (6) as follows:

$t_{1 / 2}=1 /\left(k q_{e}\right)$.

The effects of the initial PEG concentration, stirring (mixing) speed, and adsorbent size on the rate and extent of adsorption of PEG were studied at $25^{\circ} \mathrm{C}$ and are presented below.

\subsubsection{Effect of initial concentration}

The effect of the initial PEG concentration on the intake rate by zeolite DAY adsorption at adsorbent dosage of $3 \mathrm{~g}$ $3.7 \mathrm{dm}^{-3}$ and mixing speed of $800 \mathrm{rpm}$ is shown in Fig. 2, where the experimental data are shown as discrete points and those obtained from the model by solid lines. It is evident from Fig. 2 that the rate of adsorption decreased with time until it gradually approached a plateau due to the continuous decrease in the concentration driving force. The kinetic data obtained from batch studies have been analyzed using the pseudo-second-order model. Values of $k, q_{e}$, correlation coefficient $\left(R^{2}\right), t_{1 / 2}$, and $C_{e}$ for the PEG adsorption system, computed from (5)-(8), are listed in Table 2, from which it will be seen that the kinetics of PEG adsorption on zeolite DAY follows this model with regression coefficients higher than 0.99 for all the systems in this study. Clearly, the adsorption capacity (i.e., $q_{e}$ ) increases with the initial PEG concentration (i.e., $C_{0}$ ) and equilibrium concentration (i.e., $C_{e}$ ), which is also consistent with their adsorption isotherms described previously. Further, it was found that the variation of rate constant (i.e., $k$ ) and $t_{1 / 2}$ seemed to have a significant trend with initial PEG concentration.

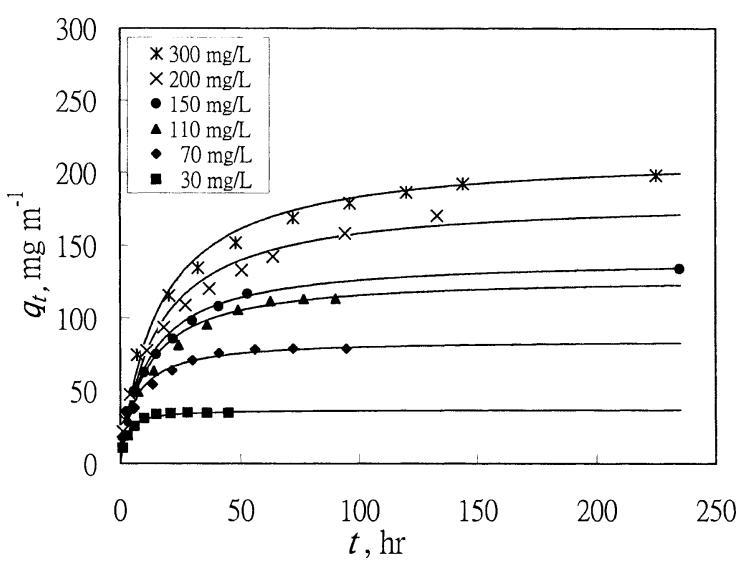

Fig. 2. Plots of adsorbed amount versus time at various initial PEG concen-

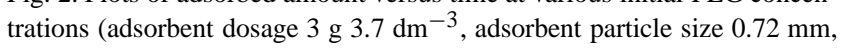
agitation speed $800 \mathrm{rpm}$, and temperature $25^{\circ} \mathrm{C}$; symbols: experimental data; full lines: calculated from Eq. (7) and Table 2).

Table 2

Kinetic parameters for adsorption of PEG onto zeolite DAY at various initial concentrations

\begin{tabular}{ccrcrr}
\hline $\begin{array}{c}C_{0} \\
\left(\mathrm{mg} \mathrm{dm}^{-3}\right)\end{array}$ & $\begin{array}{c}k \\
\left(\mathrm{~g} \mathrm{mg}^{-1} \mathrm{~h}^{-1}\right)\end{array}$ & $\begin{array}{c}q_{e} \\
\left(\mathrm{mg} \mathrm{g}^{-1}\right)\end{array}$ & $\begin{array}{c}\text { Correlation } \\
\text { coefficient }\end{array}$ & \multicolumn{1}{c}{$\begin{array}{c}t_{1 / 2} \\
(\mathrm{~h})\end{array}$} & \begin{tabular}{c}
\multicolumn{1}{c}{$\begin{array}{c}C_{e} \\
\left(\mathrm{mg} \mathrm{dm}^{-3}\right)\end{array}$} \\
\hline 30
\end{tabular} \\
0.012200 & 37.037 & 0.9987 & 2.213 & 0.000 \\
70 & 0.001961 & 84.746 & 0.9984 & 6.017 & 1.287 \\
110 & 0.000719 & 128.205 & 0.9944 & 10.848 & 6.050 \\
150 & 0.000607 & 140.845 & 0.9994 & 11.697 & 35.801 \\
200 & 0.000365 & 181.818 & 0.9905 & 15.069 & 52.580 \\
300 & 0.000293 & 212.766 & 0.9989 & 16.041 & 127.487 \\
\hline
\end{tabular}

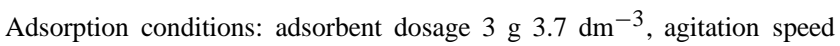
$800 \mathrm{rpm}$, and temperature $25^{\circ} \mathrm{C}$. 


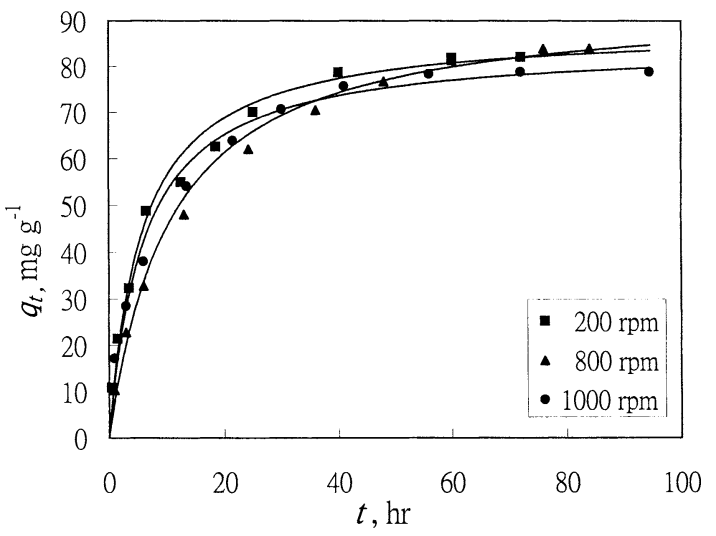

Fig. 3. Plots of adsorbed amount versus time at various agitation speeds

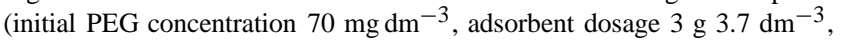
adsorbent particle size $0.72 \mathrm{~mm}$, and temperature $25^{\circ} \mathrm{C}$; symbols: experimental data; full lines: calculated from Eq. (7) and Table 3).

Table 3

Kinetic parameters for adsorption of PEG onto zeolite DAY at various agitation speeds

\begin{tabular}{cccccc}
\hline $\begin{array}{c}\text { Agitation } \\
\text { speed }(\mathrm{rpm})\end{array}$ & $\begin{array}{c}k \\
\left(\mathrm{~g} \mathrm{mg}^{-1} \mathrm{~h}^{-1}\right)\end{array}$ & $\begin{array}{c}q_{e} \\
\left(\mathrm{mg} \mathrm{g}^{-1}\right)\end{array}$ & $\begin{array}{c}\text { Correlation } \\
\text { coefficient }\end{array}$ & $\begin{array}{c}t_{1 / 2} \\
(\mathrm{~h})\end{array}$ & $\begin{array}{c}C_{e} \\
\left(\mathrm{mg} \mathrm{dm}^{-3}\right)\end{array}$ \\
\hline 200 & 0.001974 & 88.496 & 0.9973 & 5.724 & $0.000^{\mathrm{a}}$ \\
800 & 0.001961 & 84.746 & 0.9984 & 6.017 & 1.287 \\
1000 & 0.000981 & 94.340 & 0.9975 & 10.815 & $0.000^{\mathrm{a}}$ \\
\hline
\end{tabular}

Adsorption conditions: initial concentration $70 \mathrm{mg} \mathrm{dm}^{-3}$, adsorbent dosage $3 \mathrm{~g} 3.7 \mathrm{dm}^{-3}$, and temperature $25^{\circ} \mathrm{C}$.

${ }^{a}$ Values of $C_{e}$ are negative based on the rough calculation in Eq. (1).

\subsubsection{Effect of agitation speed}

The effect of agitation speed on PEG adsorption at an

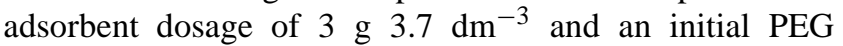
concentration of $70 \mathrm{mg} \mathrm{dm}^{-3}$ is shown in Fig. 3 and Table 3. The correlation between the experimental and the model results is again excellent. The data listed in Table 3 indicates that the adsorption capacity (i.e., $q_{e}$ ) has no significant increase and the equilibrium concentration has thus no relative decrease as the agitation speed increases from 200 to $1000 \mathrm{rpm}$. This effect can be attributed to the strong turbulence and the very small thickness around the adsorbent particles in the boundary layer as a result of the high degree of mixing [24]. However, the variation of rate constant (i.e., $k$ ) and $t_{1 / 2}$ seemed to have significant trend with the agitation speed, as depicted in Table 3 .

\subsubsection{Effect of adsorbent size}

The effect of varying the zeolite particle size on PEG adsorption at the initial concentration of $70 \mathrm{mg} \mathrm{dm}^{-3}$ and mixing speed of $800 \mathrm{rpm}$ is shown in Fig. 4. The values of rate parameters for the adsorption system have been obtained and listed in Table 4. It is evident from Fig. 4 that the correlation between the experimental and the model results is also good. It can be expected that the PEG concentration in the solution decreased and the adsorbed amount thus increased at a faster rate as the adsorbent size decreased. Table 4 shows that the adsorption capacity (i.e., $q_{e}$ ) increased and equilibrium con-

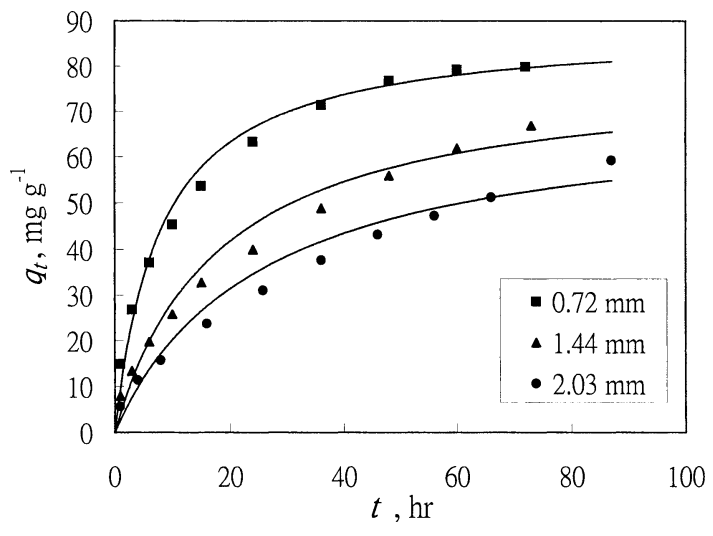

Fig. 4. Plots of adsorbed amount versus time at various adsorbent particle sizes (initial PEG concentration $70 \mathrm{mg} \mathrm{dm}^{-3}$, adsorbent dosage $3 \mathrm{~g}$ $3.7 \mathrm{dm}^{-3}$, agitation speed $800 \mathrm{rpm}$, and temperature $25^{\circ} \mathrm{C}$; symbols: experimental data; full lines: calculated from Eq. (7) and Table 4).

Table 4

Kinetic parameters for adsorption of PEG onto zeolite DAY at various adsorbent sizes

\begin{tabular}{cccccc}
\hline $\begin{array}{c}\text { Size } \\
(\mathrm{mm})\end{array}$ & $\begin{array}{c}k \\
\left(\mathrm{~g} \mathrm{mg}^{-1} \mathrm{~h}^{-1}\right)\end{array}$ & $\begin{array}{c}q_{e} \\
\left(\mathrm{mg} \mathrm{g}^{-1}\right)\end{array}$ & $\begin{array}{c}\text { Correlation } \\
\text { coefficient }\end{array}$ & $\begin{array}{c}t_{1 / 2} \\
(\mathrm{~h})\end{array}$ & $\begin{array}{c}C_{e} \\
\left(\mathrm{mg} \mathrm{dm}^{-3}\right)\end{array}$ \\
\hline 0.72 & 0.001961 & 84.746 & 0.9984 & 6.017 & 1.287 \\
1.44 & 0.000718 & 78.740 & 0.9697 & 17.688 & 6.157 \\
2.03 & 0.000573 & 70.423 & 0.9438 & 24.782 & 12.900 \\
\hline
\end{tabular}

Adsorption conditions: initial concentration $70 \mathrm{mg} \mathrm{dm}^{-3}$, agitation speed $800 \mathrm{rpm}$, and temperature $25^{\circ} \mathrm{C}$.

centration thus decreased as the adsorbent size decreased. This behavior can demonstrate that larger surface areas of adsorbent particles are associated with smaller particle size. Also, the intradiffusional resistance to mass transfer is more significant with large particle sizes and consequently most of the internal surface of the particle may not be utilized for adsorption; hence the amount of PEG adsorbed is relatively small [25]. The results obtained from this section of experiments also indicated that the rate constant $(k)$ seemed to decrease significantly as the adsorbent size increased.

\subsection{Adsorption of electroplating solution}

The purpose of electroplating solution adsorption is to evaluate the applicability of isotherm models and pseudosecond-order models described previously. The Langmuir and Freundlich parameters were computed and also are given in Table 1. It is seen that the two models still appear to fit the data well. The Freundlich model yields a somewhat better fit than the Langmuir model when the $R^{2}$ are compared (0.9944 vs 0.9660) (Fig. 5), which is consistent with the results of PEG adsorption in water solution. Comparing the values of the monolayer adsorption capacity $\left(q_{m}\right)$ of PEG adsorbed by activated carbon F-400 $\left(q_{m}=303 \mathrm{mg} \mathrm{g}^{-1}\right.$, BET surface area $\left.=1026 \mathrm{~m}^{2} / \mathrm{g}\right)$ and zeolite DAY $\left(q_{m}=\right.$ $144 \mathrm{mg} \mathrm{g}^{-1}$, BET surface area $=601 \mathrm{~m}^{2} / \mathrm{g}$ ) in electroplating solution [12], one sees that the ratio of the value of $q_{m}$ of activated carbon to that for zeolite is approximately the ratio 


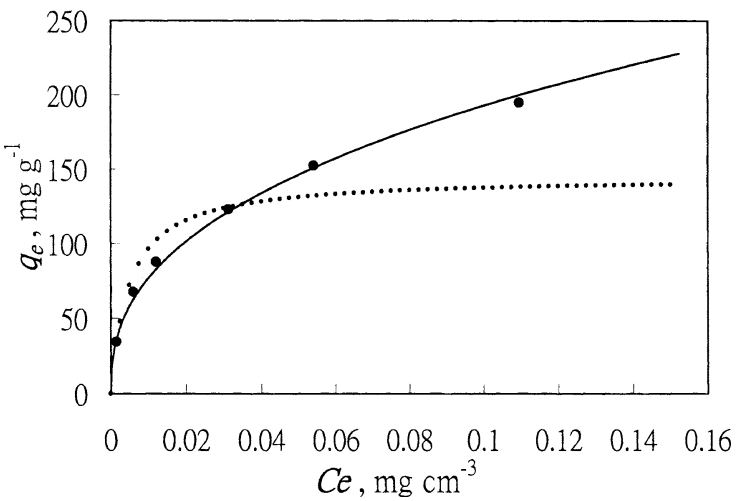

Fig. 5. Isothermal adsorption of PEG in electroplating solution onto zeolite DAY at $25^{\circ} \mathrm{C}$. - experimental data; - , simulation of Freundlich model; $\cdots$, simulation of Langmuir model.

Table 5

Kinetic parameters for adsorption of PEG onto zeolite DAY in copper electroplating solution and water solution

\begin{tabular}{lcccc}
\hline Solution & $\begin{array}{c}k \\
\left(\mathrm{~g} \mathrm{mg}^{-1} \mathrm{~h}^{-1}\right)\end{array}$ & $\begin{array}{c}q_{e} \\
\left(\mathrm{mg} \mathrm{g}^{-1}\right)\end{array}$ & $\begin{array}{c}\text { Correlation } \\
\text { coefficient }\end{array}$ & $\begin{array}{c}t_{1 / 2} \\
(\mathrm{~h})\end{array}$ \\
\hline Electroplating & 0.002079 & 96.956 & 0.9984 & 4.961 \\
Water & 0.001961 & 84.746 & 0.9984 & 6.017 \\
\hline
\end{tabular}

Adsorption conditions: initial concentration $70 \mathrm{mg} \mathrm{dm}^{-3}$, adsorbent dosage $3 \mathrm{~g} 3.7 \mathrm{dm}^{-3}$, and temperature $25^{\circ} \mathrm{C}$.

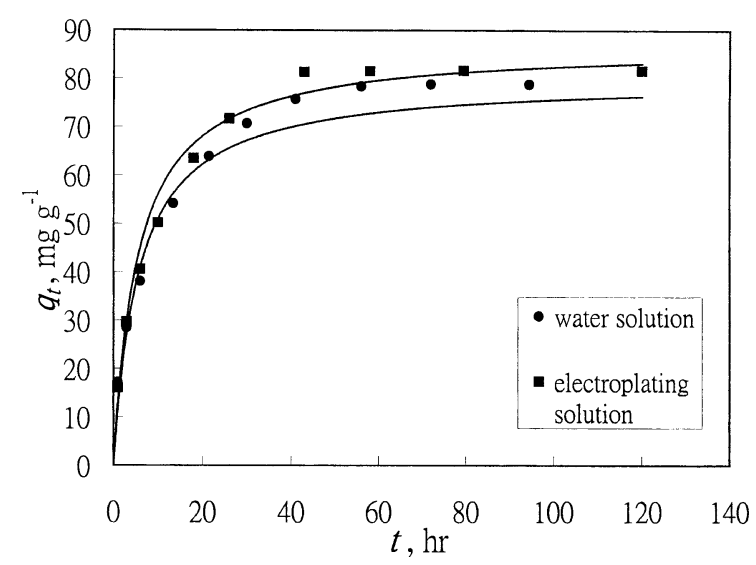

Fig. 6. Plots of adsorbed amount versus time in electroplating solution vs water solution (initial PEG concentration $70 \mathrm{mg} \mathrm{dm}^{-3}$, adsorbent dosage $3 \mathrm{~g} 3.7 \mathrm{dm}^{-3}$, adsorbent particle size $0.72 \mathrm{~mm}$, agitation speed $800 \mathrm{rpm}$, and temperature $25^{\circ} \mathrm{C}$; symbols: experimental data; full lines: calculated from Eq. (7) and Table 5).

of their surface areas. The adsorption kinetics in electroplating solution, in the other hand, are given in Table 5 under

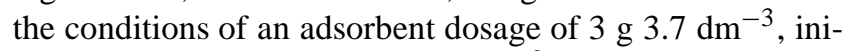
tial PEG concentration of $70 \mathrm{mg} \mathrm{dm}^{-3}$, and mixing speed of $800 \mathrm{rpm}$. Obviously, there are no significant differences between the adsorptions in electroplating solution and water solution from the data of $q_{e}, k$, and $t_{1 / 2}$ (Table 5 and Fig. 6).

\subsection{Diffusion coefficient}

According to the typical adsorption model [14,15], there are two main mass transfer resistances, external diffusion across the boundary layer surrounding each adsorbent particle and internal diffusion into the porous particle. In the previous discussion, it seems that the effect of agitation speed on the rate and capacity of adsorption is negligible in this investigation, implying that the rate of adsorption in the porous adsorbent should be controlled by transport within the pore network. For the liquid-phase diffusion of a solute with large molecular size in porous materials, its effective diffusion coefficient $\left(D_{e}\right)$ can be related to the equation describing the restrictive or hindered diffusion [26,27] as

$D_{e}=\left[D_{b} \varepsilon / \tau\right] F(\lambda)$,

where $D_{b}$ is the bulk diffusion coefficient or diffusivity in free solution, $\varepsilon$ is the porosity, $\tau$ is the tortuosity factor of the porous particle ranging from 2 to 7 [20], and $F(\lambda)$ is a function dependent on the ratio of critical molecular size and pore size (i.e., $\lambda$ ) accounting for steric hindrance/exclusion and hydrodynamic drag effects. In the present study, the bulk diffusivity of PEG in water at $25^{\circ} \mathrm{C}$ was estimated using the equation [28]

$D_{b}=1.465 \times 10^{-4} \times M_{a}^{-0.557}$,

where $M_{a}$ is the average molecular weight of PEG with the value of 6000. Substituting in Eq. (10), we obtain $1.152 \times$ $10^{-6} \mathrm{~cm}^{2} \mathrm{~s}^{-1}$ for bulk diffusivity of PEG in water. The critical molecular size is defined as the minimum cross-sectional diameter of the adsorbate molecule and may be estimated from bond lengths, bond angles, and van der Waals radii [20]. According to the side view of the PEG molecule and the data on the molecular structure [29], the critical dimension is approximately to $0.55 \mathrm{~nm}$. Therefore, the value of $\lambda$ is approximately $0.348(=0.55 \mathrm{~nm} / 1.58 \mathrm{~nm})$ based on average pore diameter, commonly calculated from the total pore volume and BET surface area [19]. For $\lambda<0.5$, a commonly used expression for the restrictive diffusion effect was derived by Renkin [30], given by

$F(\lambda)=\left(1-\lambda^{2}\right)\left(1-2.104 \lambda+2.09 \lambda^{3}-0.95 \lambda^{5}\right)$

$D_{e}$ for the intraparticle transport of PEG within the pores of zeolite DAY has been estimated to $3.204 \times 10^{-8} \mathrm{~cm}^{2} \mathrm{~s}^{-1}$ based on $D_{b}=1.152 \times 10^{-6} \mathrm{~cm}^{2} \mathrm{~s}^{-1}, \varepsilon=0.36, \tau=4$ [20] and $F(\lambda)=0.309$. The obtained value of the effective diffusivity is compared to the typical reported diffusion coefficients (ca. $10^{-8} \mathrm{~cm}^{2} \mathrm{~s}^{-1}$ ) in zeolites found in the literature [20]. Further work would be helpful in order to elucidate surface diffusion of flexible chains of PEG molecule [31] and simulate the adsorption system based on either liquid film resistance or pore diffusion resistance $[14,15]$. 


\section{Conclusions}

The use of hydrophobic zeolite for the adsorption of PEG from aqueous solutions has been examined at $25^{\circ} \mathrm{C}$. The following conclusions can be drawn:

- The adsorption isotherm can be well correlated by Langmuir and Freundlich models.

- The adsorption kinetics can be well described by the pseudo-second-order model equation.

- The effect of the initial PEG concentration and adsorbent particle size on the rate of adsorption and the equilibrium adsorption was found to be of considerable significant.

- The intraparticle diffusion mechanism plays a significant role in the adsorption system based on the results of the effect of adsorbent size on the rate of adsorption and the equilibrium adsorption capacity.

- The results of this research were found to be in agreement with those for similar adsorption systems, e.g., the PEG-activated carbon adsorption system.

- The effective diffusion coefficient, estimated based on the restrictive diffusion model, is compared to the published data in the literature.

- A feasible process option would comprise the adsorption of PEG from copper electroplating solution by hydrophobic zeolite and then recycle the bath with subsequent addition of new organic additive.

\section{Acknowledgments}

This research was partly supported by the NSC (National Science Council), Taiwan, under Contracts NSC 89-2211E-002-025 and NSC 89-2211-E-041-006. The authors also thank the Powder Technology Laboratory of Chemical Engineering Department of National Taiwan University for assistance in characterizing the zeolite adsorbent.

\section{References}

[1] T. Kobayashi, J. Kawasaki, K. Mihara, H. Honma, Electrochim. Acta 47 (2001) 85.

[2] C.L. Fang, General Concepts of Additives in the Electroplating Processes, Finishing Science, Taipei, 1996 [in Chinese].

[3] Environmental White Paper, Environmental Protection Administration (EPA), Taipei, Taiwan, 2002 [in Chinese].

[4] J. Suzuki, J. Appl. Polym. Sci. 20 (1976) 93.

[5] J. Suzuki, N. Taumi, S. Suzuki, J. Appl. Polym. Sci. 23 (1979) 3281.

[6] R. Andreozzi, V. Caprio, A. Insola, Water Res. 30 (1996) 2955.

[7] C.Y. Chang, Y.H. Chen, H. Li, C.Y. Chiu, Y.H. Yu, P.C. Chiang, Y. Ku, J.N. Chen, J. Chin. Inst. Environ. Eng. (Taiwan) 10 (2000) 69.

[8] H. Li, C.Y. Chang, C.Y. Chiu, Y.H. Yu, P.C. Chiang, Y.H. Chen, S.J. Lee, Y. Ku, J.N. Chen, J. Environ. Eng. (ASCE) 127 (2001) 908.

[9] C.H. Liao, M.C. Lu, Y.J. Chen, Y.H. Lin, P.F. Hsieh, J. Chin. Inst. Environ. Eng. (Taiwan) 12 (2002) 1.

[10] M. Suzuki, T. Kawai, K. Kawazoe, J. Chem. Eng. Jpn. 9 (1976) 203.

[11] W.B. Arbuckle, M.Y. Osman, Environ. Eng. Sci. 17 (2000) 147.

[12] C.F. Chang, C.Y. Chang, W.T. Tsai, S.C. Wu, J. Colloid Interface Sci. 232 (2000) 207.

[13] X. Zhao, K. Urano, S. Ogasawara, Colloid Polym. Sci. 267 (1989) 899.

[14] K.E. Noll, V. Gounaris, W.S. Hou, Adsorption Technology for Air and Water Pollution Control, Lewis, Chelsea, MI, 1992.

[15] G. McKay (Ed.), Use of Adsorbents for the Removal of Pollutants from Wastewater, CRC Press, Boca Raton, FL, 1996.

[16] R.C. Bansal, J.B. Donnet, F. Stoeckli, Active Carbon, Dekker, New York, 1988.

[17] S.W. Blocki, Environ. Prog. 12 (1993) 226.

[18] W.T. Tsai, C.Y. Chang, H.C. Lee, J. Environ. Sci. Health A 31 (1996) 995.

[19] J.M. Smith, Chemical Engineering Kinetics, 3rd ed., McGraw-Hill, New York, 1981.

[20] C.N. Satterfield, Heterogeneous Catalysis in Industrial Practice, 2nd ed., McGraw-Hill, New York, 1991.

[21] Y.S. Ho, C.C. Chiang, Y.C. Hsu, Sep. Sci. Technol. 36 (2001) 2473.

[22] Y.S. Ho, C.C. Chiang, Adsorption 7 (2001) 139.

[23] F.C. Wu, R.L. Tseng, R.S. Juang, Water Res. 35 (2001) 613.

[24] Z. Al-Qodah, Water Res. 34 (2000) 4295.

[25] M. El-Guendi, Adsorpt. Sci. Technol. 8 (1991) 217.

[26] A. Chantong, F.E. Massoth, AIChE J. 29 (1983) 725.

[27] D.M. Smith, AIChE J. 32 (1986) 1039.

[28] J. Shao, R.E. Baltus, AIChE J. 46 (2000) 1149.

[29] D.R. Lide (Ed.), CRC Handbook of Chemistry and Physics, 81st ed., CRC Press, Boca Raton, FL, 2000.

[30] E.M. Renkin, J. Gen. Physiol. 38 (1954) 225.

[31] S.A. Sukhishvili, Y. Chen, J.D. Muller, E. Gratton, K.S. Schweizer, S. Granick, Macromolecules 35 (2002) 1776. 